\title{
Me Against Myself: Motivational Conflicts and Emotional Development in Adulthood
}

\author{
Michaela Riediger \\ Max Planck Institute for Human Development
}

\author{
Alexandra M. Freund \\ University of Zurich
}

\begin{abstract}
Two studies investigated adult age differences in the frequency and emotional consequences of motivational conflicts (i.e., feeling that one wants to or should do something else in a given situation). Study 1 compared younger and older adults. Study 2 included a more age-heterogeneous sample ranging from 20 to 70 years. Data were obtained using diary and experience-sampling methods. Multilevel regression showed that motivational conflict was associated with lower emotional well-being. With age, the frequency of motivational conflict decreased, while emotional well-being increased. Importantly, the age-related decrease in motivational conflicts partly accounted for the age-related increase in emotional well-being. Findings were consistent across studies and robust after the authors controlled for age differences in a number of control variables including time use. The authors conclude that an age-related decrease in motivational conflicts in daily life may be among the factors underlying the positive development of emotional well-being into older adulthood.
\end{abstract}

Keywords: motivational conflict, emotional well-being, diary, experience sampling
Motivational conflicts are ubiquitous in everyday live. People often encounter situations in which they are caught on the horns of dilemma-they need to meet an urgent deadline but want to go to a friend's party too; they wish to be punctual for a concert but also feel they should take time for a friend who just called with a problem. In the present research, we investigated the role that such day-to-day motivational conflicts might play in emotional wellbeing across adulthood.

Because of its prominent role in human experience, the topic of intrapsychic conflict-or opposing tendencies within an individual-has a long history in psychological theory and research. Evidence is overwhelming that intraindividual conflict, regardless of its specific manifestation, is detrimental to an individual's well-being, both in the nonpathological and pathological range (e.g., Allen, Herst, Bruck, \& Sutton, 2000; Higgins, Klein, \& Straumann, 1987; Michalak, Heidenreich, \& Hoyer, 2004). In this article, we focus on motivational conflict as one instance of intraindividual conflict. To date, motivational conflicts have primarily been studied in terms of problems among an individual's longer term goals. In this research, participants typically report their personal goals and then evaluate the nature of interrelations among

We thank Berndt Wischnewski for programming the ExperienceSampling software; Ulrike Altmann, Monika Chojnowska, Dulce Erdt, Wolfgang Gaißmaier, Sanja Hodzic, Axinja Kalusche, Poldi Kuhl, Antje Rauers, Max Rotter, and Cornelia Wrzus for their help in conducting the studies; and Julia Delius for improving the English of this article. We also appreciate the time and effort the participants invested in this research.

Correspondence concerning this article should be addressed to Michaela Riediger, Center for Lifespan Psychology, Max Planck Institute for Human Development, Lentzeallee 94, 14195 Berlin, Germany, or to Alexandra M. Freund, Department of Psychology, University of Zurich, Binzmuehlestrasse 14/11, CH-8050 Zurich, Switzerland. E-mail: riediger@mpib-berlin.mpg.de or freund@psychologie.uzh.ch these goals (e.g., Emmons \& King, 1988; Riediger \& Freund, 2004). Perceptions of conflict among goals can result from resource constraints (e.g., when several goals require more of the same resource, such as time, than is available) or from incompatible goal attainment strategies (Riediger \& Freund, 2004). Provided that assessment techniques differentiate between conflict and mutual facilitation, empirical evidence clearly confirms that conflict among higher level goals is associated with impaired psychological well-being (whereas facilitation among goals is unrelated to well-being but detrimental to behavioral involvement in goal pursuit; for a review, see Riediger, 2007).

Most of this research has been conducted in samples of younger adults (typically college students). The little developmental evidence available demonstrates that older adults perceive their goals as more mutually facilitative than younger and middle-aged adults (Riediger \& Freund, 2006; Riediger, Freund, \& Baltes, 2005). There are also some suggestions that older adults experience less conflict between goals than do younger adults (Kehr, 2003; Locke, Smith, Erez, Chah, \& Schaffer, 1994). However, this has not been supported consistently in other research and more representative samples (Riediger et al., 2005).

Although instructions vary, assessment procedures of higher level goal conflict generally require construction processes on a fairly high level of abstraction. To aggregate a summary judgment of the extent of mutual conflict among their longer term goals, people need to compare different mental simulations of what pursuing these goals entails. Potential differences between such abstract constructions of conflict among higher level goals and actual conflict experiences in everyday life could be one of the reasons for the inconclusive results on age-related differences to date. In the present research, we therefore investigated experiences of momentary motivational conflicts as they occur in people's natural environments and their potential role in the affective dayto-day lives of adults of different ages. 
Motivational Conflicts in Day-to-Day Life: "Wants" and "Shoulds"

Motivational conflicts in everyday life frequently result from the co-occurrence of behavioral tendencies that cannot be followed simultaneously, so that one tendency has to be given priority at the cost of the other for the time being. Depending on the behavioral option chosen, such motivational dilemmas can lead to the sense that one wants to do something else (e.g., because that would be more pleasurable) or that one should do something else instead (e.g., because that would be more responsible). One and the same situation might thus elicit either want or should conflict in the individual. In our conceptualization, the primary distinction between both types of conflicts is the individual's specific experience, which we assume to be grounded in the behavioral decisions that people make in such forced-choice situations. A student facing an important exam might decide to spend the night studying but at the same time feel that she rather wants to go to the movies. Deciding to go out, in contrast, might elicit the feeling that she should spend that time studying.

O'Connor et al. (2002) argued that people often experience intrapersonal conflict as tension between what they want to do and what they think they should do. In their want-should distinction, the "want self" is more impulsive and concerned with satisfying short-term interests, such as immediate pleasure, whereas the "should self" is more reasoned and concerned with pursuing longer term interests. Although various authors have highlighted wants and shoulds as prototypical instances of motivational-conflict experiences (e.g., Bazerman, Tenbrunsel, \& Wade-Benzoni, 1998; Loewenstein, 1996; O'Connor et al., 2002), so far, their frequency and affective consequences have neither been studied in people's daily lives and natural environments nor have they been studied from a developmental perspective.

In the present research, we aimed to fill this gap by addressing three interrelated questions: (a) Are there age-related differences in the frequency of want and should conflicts in daily lives of adults of various ages? (b) What are the internal and external contexts in which day-to-day want and should conflicts occur? (c) Do agerelated differences in motivational-conflict frequency account for age differences in day-to-day emotional well-being?

\section{Age-Related Differences in Day-to-Day Motivational Conflicts}

We hypothesized that motivational want and should conflicts are less prevalent in daily lives of older compared to younger adults. This prediction is based on two interrelated considerations. First, older adults have been shown to be more selective than younger adults. For example, they report fewer goals and possible selves than younger adults, and they focus their motivational commitments more on subjectively important life domains and on goals that are similar to each other (e.g., Cross \& Markus, 1991; Freund \& Baltes, 2002; Riediger \& Freund, 2006; Staudinger, Freund, Linden, \& Maas, 1999). Reasoning that higher selectivity should be associated with a lower likelihood of simultaneously occurring but incompatible behavioral tendencies, we expected a lower frequency of everyday motivational-conflict experiences in older than in younger adults. Second, whereas social expectations and contextual constraints structure and prescribe daily pursuits in younger adulthood (e.g., Settersten \& Hagestad, 1996a, 1996b), in older adulthood, social expectations are less clear and roles are less explicitly defined (e.g., Riley, Kahn, \& Fohner, 1994). Accordingly, older adults should have, in principle, a larger freedom in deciding which long-term and situational goals to pursue (Freund, 2006). On the basis of these considerations, we expected older adults to encounter fewer occasions in their daily lives in which behavioral tendencies require prioritization. As a consequence, they should be less likely than younger adults to experience day-to-day motivational conflicts of feeling that they want to or should do something other than the chosen behavioral option.

\section{Contexts of Experiencing Want and Should Conflicts}

Another aim of the present research was to explore the contexts associated with want and should conflicts. Two potential context factors were already mentioned above: We assumed higher selectivity to be associated with fewer day-to-day motivational-conflict experiences, and social expectations and constraints to be associated with a higher likelihood of want and should conflicts. Reasoning that sociocultural structures are most influential during the working week, we assumed want and should conflicts to be more prevalent during the week than during weekends for younger adults, and age-related differences in motivational-conflict prevalence to be attenuated on weekends.

We further expected want and should conflicts to be less likely in situations in which persons are explicitly focused on pursuing one particular objective, independent of their age. This prediction is based on empirical evidence showing that such a specific goal focus induces an implemental mind-set that tunes the person to processing information in a manner that facilitates and shields goal pursuit. Individuals in implemental mind-sets tend to disregard or devaluate information that might question the feasibility and desirability of a chosen goal (Gollwitzer, Fujita, \& Oettingen, 2004). Thus, we expected individuals to be less likely to recognize potentially conflicting behavioral options in situations in which they are explicitly focused on the pursuit of a particular outcome.

Implemental mind-sets can be disrupted when chosen goals are blocked (Henderson, Gollwitzer, \& Oettingen, 2007). In such situations, persons will eventually return to a deliberative mindset, that is, will attend to all available options and deliberate which of them might yield the best outcomes (Gollwitzer et al., 2004). We therefore expected persons, regardless of their age, to be more likely to realize a potential co-occurrence of conflicting behavioral tendencies and experience motivational conflicts when they are faced with obstacles than when they are not.

\section{Day-to-Day Motivational Conflicts and Emotional Well-Being}

Finally, we were also interested in the role of day-to-day motivational conflicts for emotional development in adulthood. There is increasing evidence that older adults report at least comparable, often even higher levels of emotional well-being than younger adults (e.g., Birditt \& Fingerman, 2003; Carstensen, Pasupathi, Mayr, \& Nesselroade, 2000; Charles, Reynolds, \& Gatz, 2001; Gross et al., 1997; Horley \& Lavery, 1995; Lawton, Kleban, \& Dean, 1993; Levenson, Carstensen, \& Gottman, 1993; Stacey \& Gatz, 1991). To date, most attempts to explain adult trajectories in 
emotional well-being focus on the notion of resilience, that is, on older adults' ability to adjust to losses and major life events. Research in this tradition has emphasized the adaptive value of regulatory processes such as social downward comparisons, goal adjustment and goal disengagement, and active problem-solving strategies (Staudinger, 2000).

We propose that in addition to the ability to deal with major life events, age-related differences in managing mundane day-to-day experiences might also contribute to the high levels of emotional well-being across adulthood. In the present research, we investigated this hypothesis using the prevalence of day-to-day motivational conflict as a sample characteristic of people's daily lives that might influence emotional well-being. Specifically, we assumed that occurrences of want and should conflicts are accompanied by impaired emotional well-being. This prediction is in line with the above-mentioned empirical evidence for the association of higher level goal conflict and lower subjective well-being (for a review, see Riediger, 2007) as well as with models that ascribe affect a regulatory function in action processes (e.g., Bagozzi, Baumgartner, \& Pieters, 1998). These models propose that negative affect signals threat to goal attainment and that it enhances activities directed at the resolution of this problem. Integrating this prediction with the above-introduced hypothesis that motivational want and should conflicts are less prevalent in daily lives of older compared to younger adults, we assumed a lower prevalence of motivational-conflict experiences to be among the mechanisms underlying positive age differences in emotional well-being.

\section{Summary and Overview of the Current Studies}

We were motivated in the present research by an interest in the role that day-to-day motivational conflict experiences (i.e., feeling that one wants or should do something else) might play in adults' emotional well-being. We predicted that motivational-conflict experiences are more prevalent in younger than in older adults. This prediction was based on the assumption that older adults are more behaviorally selective and less subject to social expectations and behavioral prescriptions than younger adults. We therefore expected age differences in motivational-conflict prevalence to be attenuated on weekends compared to weekdays. We also predicted that, independent of the individuals' age, want and should conflicts are less likely when individuals are focused on the pursuit of a particular outcome and more likely when individuals are faced with obstacles. We further hypothesized that want and should conflicts are associated with impaired emotional well-being and that the decrease in day-to-day motivational conflict prevalence is among the factors that contribute to better emotional well-being in older compared to younger adults.

We conducted two studies to test our predictions. In Study 1, we compared younger and older adults. In Study 2, we investigated a sample of adults covering the age range from 20 to 70 years. To decrease sampling bias in the latter sample, we worked with a survey company and used stratified random digit dialing as recruitment strategy. In both studies, our methodological aim was to maximize ecological validity. We took two complementary approaches to meet this aim. In Study 1, participants kept comprehensive activity diaries spanning their entire waking day. In Study 2, we used experience sampling to obtain repeated reports of participants' momentary experiences.
Study 1

Method

\section{Participants}

Participants were 81 adults (younger: $n=52,20.1-35.4$ years, $M=25.9$; older: $n=29,58.9-78.1$ years, $M=64.3)$. The sample was predominantly female (67\% women in the younger and $83 \%$ in the older subsample). The majority of the younger participants were university students (75\%), and most of the older participants had retired (79\%). Eighty-nine percent of the younger and $28 \%$ of the older participants had 12 or more years of education. For reasons not relevant in the context of the present article, all participants were exercise beginners.

\section{Procedure}

Following an instruction session, participants kept nine diaries over three periods of 3 consecutive days. Intervals of 6 days separated the diary periods. Diary periods covered 6 weekdays (Monday-Friday) and 3 weekend days (Saturday or Sunday).

Each diary consisted of three entries to be completed at noon, at 6 p.m., and immediately before going to bed. Participants received a portable alarm clock to ensure punctual completion. They also received nine prestamped return envelopes and were instructed to mail each diary on the day after its completion. To minimize missing data, we had participants complete an additional diary for each incomplete diary they provided. Five younger and 11 older participants kept one additional diary, 2 younger and 2 older participants kept two additional diaries, and 2 younger participants kept three additional diaries. With the exception of 1 participant who discontinued participation after completion of the first diary period, no participants dropped out. Participants were reimbursed 145 DM (approximately US\$65).

In each diary entry, participants rated their emotional well-being during the preceding hours (i.e., since waking up for the first diary entry, and since the preceding diary entry for the second and third diary entries) and reported the activities in which they had engaged during that time. For each activity, participants indicated starting and ending times, whether they would have liked to do something else instead (and if so, what this would have been), and whether they should have done something else instead (and if so, what this would have been). Participants further responded to some other questions that are not relevant in the present context.

Michaela Riediger assigned the reported activities to 45 content categories, which were subsequently summarized into 6 overarching categories: (a) basic and instrumental activities (e.g., self-care, meals, household chores, etc.), (b) leisure activities (e.g., hobbies, leisure reading, watching TV, etc.), (c) social contacts (e.g., conversations, visits, etc.), (d) work-study-related activities, (e) passive phases (e.g., sleeping), and (f) other. A second coding of $10 \%$ (i.e., 75) of the diaries by an independent, trained rater demonstrated high coding reliability. Agreement between the first and second coder according to Cohen's kappa was .95 .

\section{Instruments}

Affect balance. The short version of the Multidimensional Affect Rating Scale (Steyer, Schwenkmezger, Notz, \& Eid, 1997) 
includes 12 items (adjectives) assessing positive mood-negative mood, ease-restlessness, and alertness-fatigue. Participants indicated how much they had experienced each emotion since waking up (for the first diary entry) or since the preceding diary entry (for the second and third diary entries) on a scale ranging from 1 (not at all) to 5 (very much). Within participants, averages of the items with positive valence (Positive Affect, $M=2.07, S D=0.51$ ) correlated highly with averages of the items with negative valence (Negative Affect, $M=3.14, S D=0.34$; average within-person $r=-.74, S D=.17)$. This warrants the aggregation of an indicator of affect balance (Positive Affect-Negative Affect) that we report here in the interest of parsimony, and because Positive Affect and Negative Affect scores did not yield differential patterns of results. The within-person Cronbach's alpha of this aggregate measure across days was $M=.85(S D=.08)$.

Motivational-conflict experiences. For each reported activity, participants indicated whether they would have liked to do something else (referred to below as want conflict) and whether they should have done something else instead (referred to below as should conflict). Forty-six younger participants $(88.5 \%)$ and 16 older participants $(55.2 \%)$ reported occurrences of should conflicts, and 51 younger participants $(98.1 \%)$ and 26 older participants $(89.7 \%)$ reported occurrences of want conflicts. To characterize the occurrence of motivational-conflict experiences, we determined the percentage of durations (relative to the total time window of the respective diary entry) of activities within each of four categories: (a) no conflict, (b) want conflict, (c) should conflict, and (d) simultaneous want-and-should conflict (which can arise if more than two motivational tendencies compete). We used percentage of (rather than absolute) durations of conflict experiences to account for variation in the time window covered by the various diary-entry reports.

Time use. We determined the percentages of time within a given diary-entry time window that participants had spent with (a) basic-instrumental, (b) leisure, (c) study-work, and (d) socialcontact activities and (e) with passive phases. Multilevel regression analyses (analytic procedures described in detail in the Results section below) showed that there were significant age-group differences $(p s<.01)$ in the average percentages of time spent with basic-instrumental activities (younger $<$ older adults), leisure activities (younger $<$ older adults), and study-work activities (younger $>$ older adults). We therefore included these three activity indices in analyses investigating the role of age-group differences in time use.

Behavioral selectivity. Using the activity taxonomy described above, we determined the number of different types of activities reported per diary entry as an indicator of behavioral selectivity. Multilevel regression analyses showed that older adults engaged in fewer activity types per diary entry (i.e., were more selective) than younger adults $(p<.05$; older adults: average within-person $M=$ $2.90, S D=0.28$; younger adults: average within-person $M=3.07$, $S D=0.32)$. There were no age-group differences $(p>.10)$ in the absolute number of activities reported per diary entry (average within-person $M=9.08, S D=1.24)$.

Exploration of time-related trend. There were no systematic time-related trends in affect balance or in the percentage of durations of should and simultaneous should-and-want conflicts throughout the diary phase. There was, however, a small linear decrease in the percentage of durations of want conflicts through- out the study interval (accounting for $0.91 \%$ of the within-person residual variance). ${ }^{1}$ We therefore considered diary-entry number (counting from zero) as a control variable in our analyses.

Subjective health. We used the Health Evaluation subscale of the Multidimensional Body-Self Relations Questionnaire (Brown, Cash, \& Mikulka, 1990) to assess participants' subjective evaluations of their physical health, included as a control variable in this research. The scale consists of six items that are responded to on a 5-point rating scale ranging from 1 (definitely disagree) to 5 (definitely agree; $M=3.55, S D=0.76$, Cronbach's $\alpha=.84$ ). Participants responded to this scale prior to participating in the diary phase.

\section{Results}

\section{Age-Group Differences in Affect Balance and Motivational-Conflict Experiences}

To investigate whether younger and older participants differed from each other in their everyday emotional well-being and in the occurrence of everyday motivational-conflict experiences, we analyzed whether age-group membership was predictive of participants' affect balance and of the percentage of durations within a given diary-entry time window during which participants experienced different forms of motivational conflicts.

The available data had two characteristics with implications for appropriate data analysis: (a) The data structure was hierarchical with, on average, 27 repeated diary entries nested within participants. (b) The time intervals between diary entries were not equal (because diaries were kept during three periods of 3 consecutive days that were interspersed by breaks of 6 days). To accommodate for these characteristics, we used multilevel regression models fitting a time-series-type residual covariance structure appropriate for unequally spaced repeated measures. Specifically, we used SAS PROC MIXED (SAS Institute, 2002) and restricted maxi-

\footnotetext{
${ }^{1}$ Intensive repeated assessment may potentially result in reactivitycaused shifts in the mean levels of observed variables over time. In order to examine whether such time-related trends were observable in our data, we used SAS PROC MIXED, restricted maximum likelihood, and spatial power law residual covariance structure to run a series of multilevel models (see Results section for detailed description of the multilevel analytic approach taken in this research). Dependent variables in these analyses were affect balance and the percentage of durations of various types of motivational conflict. In the no-change (i.e., intercept-only) models, no predictors were included. In the linear-change models, diary-entry number, counting from zero, was included as a single predictor, and in the quadratic-change models, diary-entry number, counting from zero, and squared diary-entry number were included as predictors (cf. Singer \& Willet, 2003). Likelihood ratio tests on the change in deviance revealed no significant improvements in model fit from the no-change to the linear and quadratic-change models in the prediction of (a) affect balance and of (b) percentage of durations of should and (c) simultaneous should-and-want conflicts, indicating the absence of systematic time-related trends in these variables. In the prediction of the percentage of duration of want conflict, however, a linear-change model fitted the data best, indicating a small linear decrease in the percentage of durations of want conflicts throughout the study interval (accounting for $0.91 \%$ of the within-person residual variance). We further explored potential age-group differences in the linear and quadratic trend models. There were none in any of the models (i.e., interactions with age group were not significant, $p \mathrm{~s}>.05$ )
} 
mum likelihood to fit the spatial power law residual covariance structure to the data. Using spatial power law requires specifying a continuous time-in-study variable that references measurement times. We defined the scale of this variable such that each day of the entire diary study (including breaks) represented three units. ${ }^{2}$

Conceptually, multilevel regression models represent hierarchical systems of regression equations, which express the dependent variables using a pair of linked models; in our case, one at the diary-entry level and one at the person level. On the diary-entry level, intercepts (i.e., averages of the outcome variables) were assumed to vary across individuals. On the person level, we introduced age-group membership (younger adults $=0$, older adults $=1$ ) as a predictor of the random intercept. Parameter estimates of the combined multilevel models are summarized in Table 1. The interpretation of the fixed effects is equivalent to standard regression analyses. That is, intercepts $\left(\gamma_{00}\right)$ represent the average level in the outcome variable in the younger subsample, and the regression coefficients for age group $\left(\gamma_{01}\right)$ denote the difference in the outcome between older and younger participants (i.e., $\gamma_{00}+\gamma_{01}=$ average of the outcome variable in the older subsample). Interpretation of the variance components is more complex. The intercept variance $\left(u_{0 j}\right)$ indicates the betweenpersons variance in the outcome variable remaining after we controlled for age-group membership. The residual variance $\left(r_{i j}\right)$ indicates the within-person variance. SP(POW) is the spatial power law autoregressive parameter and indicates the estimated covariance of two adjacent diary entries in the same diary period.

Table 1

Age-Group Differences in Emotional Well-Being and Percentage of Durations of Motivational Conflict Experiences in Study 1

\begin{tabular}{|c|c|c|c|c|}
\hline \multirow[b]{2}{*}{ Model parameter } & \multicolumn{4}{|c|}{ Prediction of } \\
\hline & $\begin{array}{l}\text { Affect } \\
\text { balance }\end{array}$ & Want & Should & $\begin{array}{l}\text { Want and } \\
\text { should }\end{array}$ \\
\hline \multicolumn{5}{|l|}{ Fixed effects } \\
\hline Intercept $\left(\gamma_{00}\right)$ & $0.90^{* * *}$ & $9.46^{* *}$ & $6.53^{* *}$ & $1.40^{* *}$ \\
\hline Age group $\left(\gamma_{01}\right)^{\mathrm{a}}$ & $0.43^{* * *}$ & $-5.01^{* * *}$ & $-3.98^{* * *}$ & $-1.32^{* *}$ \\
\hline \multicolumn{5}{|l|}{ Variance components } \\
\hline Intercept $\left(u_{0 j}\right)$ & $0.37^{* * *}$ & $23.35^{* *}$ & $19.57^{* * *}$ & $1.58^{* *}$ \\
\hline $\mathrm{SP}(\mathrm{POW})^{\mathrm{b}}$ & $0.39^{* * *}$ & $0.08^{* * *}$ & $0.04 *$ & $0.13^{* *}$ \\
\hline Residual $\left(r_{i j}\right)$ & $1.34^{* * *}$ & $236.14^{* *}$ & $192.47^{* *}$ & $38.04^{* *}$ \\
\hline \multicolumn{5}{|l|}{ Modeled variance ${ }^{\mathrm{c}}$} \\
\hline $\begin{array}{l}\text { Between persons } \\
\text { pseudo }\left(R_{\text {Intercept }}^{2}\right)\end{array}$ & $9.12 \%$ & $18.72 \%$ & $19.00 \%$ & $14.43 \%$ \\
\hline
\end{tabular}

Note. Restricted maximum likelihood parameter estimates and approximate $p$ values after fitting multilevel regression models with spatial power law residual covariance structures. Motivational conflicts are reported in terms of time percentages relative to total time covered by the respective diary entry (i.e., no conflict $=$ percentage of duration of activities with no associated motivational conflicts, want $=$ percentage of duration of activities associated with want conflicts, should $=$ percentage of duration of activities associated with should conflicts, want and should = percentage of duration of activities with simultaneously associated want-and-should conflicts).

${ }^{\mathrm{a}}$ Coding: $0=$ younger participants, $1=$ older participants. ${ }^{\mathrm{b}}$ Autoregressive parameter SP(POW): Estimated covariance of two adjacent diary entries in the same diary period. ${ }^{\mathrm{c}}$ Proportional reductions in the variance component intercept in comparison to unconditional means models (i.e., models without explanatory variables).

${ }^{*} p \leq .05 . \quad{ }^{* *} p<.01$.
The numeric values of these variance components have no interpretable absolute meaning (Singer \& Willet, 2003). Of interest, in addition to the information whether parameter estimates of the variance components are significantly larger than zero, is the comparison of the intercept variance $\left(u_{0 j}\right)$ obtained in a given model to that obtained in a model without predictor variables, showing how much residual between-person variance in the outcome variable is explained by age group.

The left column of Table 1 shows that both younger and older participants reported, on average, more intense positive than negative affect. This positive affect balance was significantly more pronounced among older than among younger participants (see Figure 1), with age-group membership accounting for $9.12 \%$ of the between-persons variance in average affect balance. Significant age-group effects were also evident in the occurrence of motivational conflict experiences (see other columns of Table 1). Overall, motivational conflicts occupied smaller percentages of the older compared to the younger adults' time. The size of these effects was substantial, with age-group membership accounting for $18.7 \%$, $19.0 \%$, and $14.4 \%$ of between-persons residual variations in the average time percentages of want, should, and simultaneous wantand-should conflicts, respectively. In both age groups, want conflicts were comparably more prevalent than should conflicts, and simultaneous occurrences of want and should conflicts were rare (see Figure 2). Consequently, average time percentages without motivational conflicts were significantly smaller within younger (on average $82 \%$ of a diary-entry time window) than within older participants (on average $92 \%$ of a diary-entry time window), accounting for $19.92 \%$ of the residual between-persons variance. All obtained age effects were robust after we controlled for potential trend-related effects across diary entries and for subjective health. We tested this by including the sequential number of the diary entry (counting from zero) as an additional random predictor on the diary-entry level, and by including participants' subjective health evaluation (grand-mean centered) as an additional predictor of the random intercept.

In a next step, we extended the models predicting motivational-conflict occurrence by including participants' behavioral selectivity (i.e., the number of activity types participants had engaged in during the diary-entry time window,

\footnotetext{
${ }^{2}$ To accommodate the potentially complex dependencies among unequally spaced observations, we had conducted preliminary analyses to determine which of three alternative residual covariance structures best fitted the unconditional means variants of each of the tested model. Variance components assumes that residuals are mutually independent across occasions and persons (i.e., that all observations within a given participant are equally correlated). First-order autoregressive and spatial power law (SP[POW]), in contrast, assume that there is covariance among residuals that becomes smaller the further apart two measurements were taken. With first-order autoregressive, measurement times are consecutively numbered and referenced by their serial position in the time series, thus disregarding potential differences in time intervals between assessments. With SP(POW), measurement times are referenced by a continuous time-in-study variable that takes potentially uneven time intervals into account. Sample log-likelihood statistic, Akaike's information criterion, and Bayesian information criterion unanimously indicated superior, and in one instance comparable, goodness of fit for models fitting SP(POW) residual covariance structures (cf. Singer \& Willet, 2003).
} 


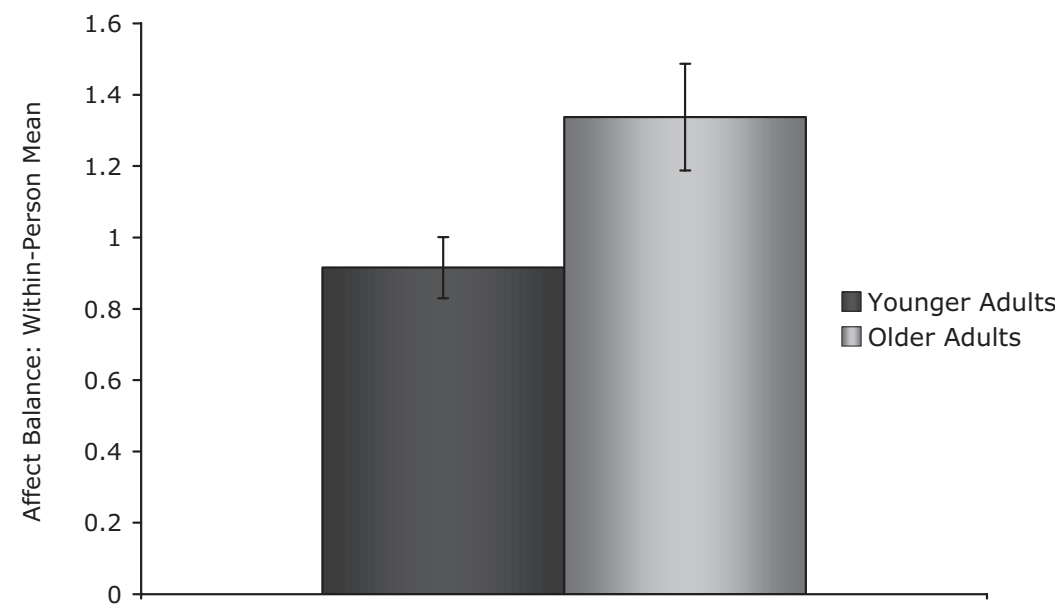

Figure 1. Study 1: Age-group differences in affect balance (within-person means across all diary entries). Error bars represent two standard errors of the mean.

grand-mean centered); the time percentages that participants had spent with basic-instrumental activities, leisure activities, and work-study activities (grand-mean centered); as well as a dummy variable coding whether the measurement was taken on a weekday or during a weekend as additional predictors on the diary-entry level. Slopes of these additional predictor variables were allowed to vary across individuals. The effects of agegroup membership remained significant in each of these analyses $(p s<.01)$. Contrary to our expectations, behavioral selectivity and weekday versus weekend were not predictive of motivational-conflict occurrence in any of these analyses ( $p s>$ .05 ). Follow-up analyses further revealed that our assumption of attenuated age effects on motivational-conflict occurrence during weekends was also not supported (i.e., Age Group $\times$ Weekend [Yes, No]: $p$ s $>.10$ ).

\section{Contents of Motivational-Conflict Experiences in Younger and Older Adults}

In the next series of analyses, our purpose was to understand the content of motivational conflicts that younger and older participants experienced in their everyday lives. What did participants do when they experienced want or should conflicts (i.e., when they wanted to do or should do something other than the activity they actually engaged in)? And what was it that they preferred to do or should have done instead? In other words, which types of everyday activities were sources and which were targets of motivational conflict experiences?

To understand sources of motivational conflict experiences, we determined the within-person percentages to which should and want conflicts occurred while a person engaged in different types

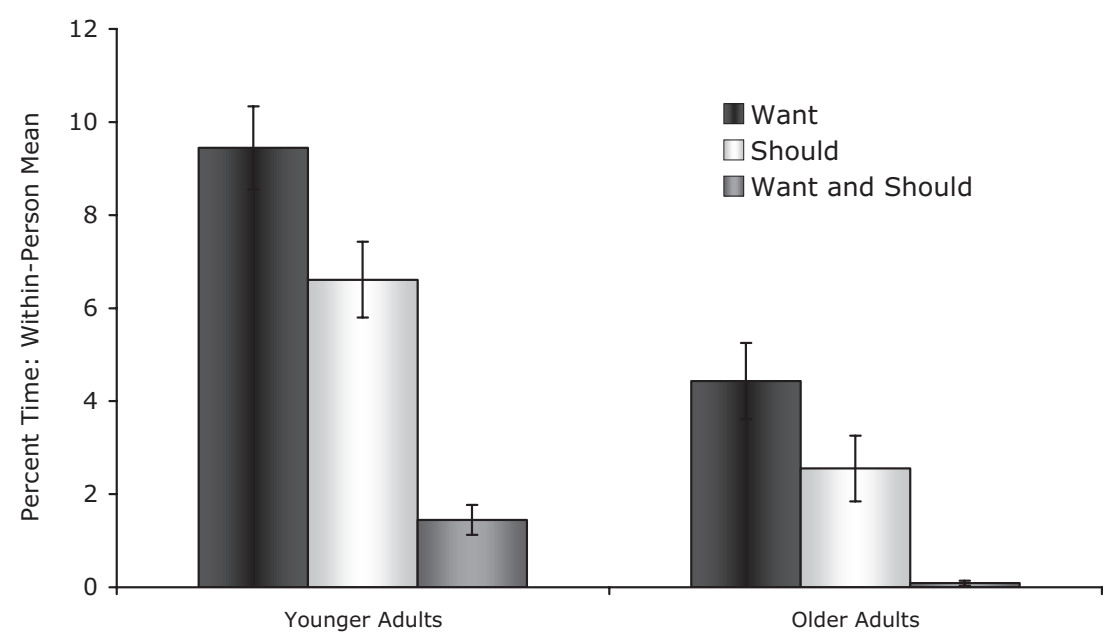

Figure 2. Study 1: Age-group differences in within-person means of percentage of durations of motivational conflicts (relative to total time window covered by a given diary entry). Error bars represent two standard errors of the mean. 
of activities (relative to the total number of should- and wantconflict occurrences within that person, respectively; see Table 2). Similarly, in order to understand targets of motivational conflicts, we determined the within-person percentages to which a person reported that he or she should have engaged in or would have wanted to engage in various types of alternative activities (relative to the total number of should- and want-conflict occurrences within that person, respectively; see Table 3 ).

As is evident from the left part of Table 2, the distribution patterns of source activities for should conflicts were relatively similar for younger and older adults. In both younger and older adults, the vast majority of should conflicts occurred when participants engaged in leisure and in basic-instrumental activities. The left part of Table 3 summarizes the targets of should conflicts, that is, participants' reports of what it was that they should have done. In the younger subsample, the most prevalent target of should conflicts was engagement in work-study-related activities, whereas in the older subsample, it was engagement in leisure activities and engagement in basic-instrumental activities.

The vast majority of want conflicts occurred during engagement in basic-instrumental activities, both in younger and older participants. In the younger subsample, the second most prevalent source of want conflicts was engagement in work-study-related activities, whereas in the older subsample, the second most prevalent source was engagement in leisure activities (see right part of Table 2). The right part of Table 3 summarizes participants' reports of what it was that they had rather wanted to do. The most prevalent targets of want conflicts were passive phases (i.e., sleeping or doing nothing) and leisure activities, both in younger and in older adults.

\section{Affective Reactivity to Motivational-Conflict Experiences}

In the series of analyses described next, we addressed two questions: Were experiences of motivational conflicts associated with participants' concurrent emotional well-being? And do these associations hold when we controlled for individuals' average affect balance?

At the diary-entry level, we predicted participants' momentary affect balance using percentage of durations of want, should, and simultaneous want-and-should conflicts (relative to the total dura- tion of the respective diary-entry time window) as independent variables (grand-mean centered). Intercept (i.e., average affect balance) and slopes (i.e., strength of the relations of momentary conflict experiences to momentary affect balance) were assumed to vary across individuals. On the person level, we expressed the random intercept and the random slopes by introducing age-group membership (younger adult $=0$; older adult $=1$ ) as a person-level predictor. Parameter estimates of the resulting multilevel model are summarized in the left column of Table 4. The interpretation of the fixed effects is equivalent to standard regression analyses: The intercept represents the average affect balance when all predictors are zero, and the slopes denote the differential in momentary affect balance for a one-unit increase in a given predictor variable when all other predictors are zero (i.e., when controlling for the effects of the other predictor variables). Variance components include estimates of the conditional between-persons $\left(u_{0 j}\right)$ and withinperson $\left(r_{i j}\right)$ variance in affect balance after controlling for all model predictors as well as estimated conditional variances in the effects of the time-varying model predictors $\left(u_{i j}\right)$ and an estimate of the spatial power law autoregressive component SP(POW) Again, the numeric values of the variance components have no interpretable absolute meaning (Singer \& Willet, 2003) beyond the information of whether they are significantly larger than zero. They are, however, of interest in comparison to those obtained in reduced model variants excluding predictors, which give information on the amount of variance explained.

Results shown in the left column of Table 4 indicate that the frequency of two of the three types of motivational-conflict experiences-want and simultaneous want-and-should conflicts-were predictive of impairments in participants' concurrent emotional well-being. Participants' momentary affect balance was more impaired the longer experiences of want and simultaneous want-andshould conflicts lasted within a given diary-entry time window. The relative duration of should conflicts was not predictive of individuals' momentary affect balance over and above the other model predictors. Inspection of the interaction terms depicted in the left column of Table 4 reveals that younger and older adults did not differ in their affective reactivity to should and simultaneous want-and-should conflicts but that the affective reactivity to want conflicts was more pronounced among younger than among older

Table 2

What Did Participants Do When They Experienced Motivational Conflict? Proportional Within-Person Distributions of Source Activities of Should and Want Conflicts in Younger and Older Adults in Study 1

\begin{tabular}{|c|c|c|c|c|c|c|c|c|c|c|}
\hline & \multicolumn{5}{|c|}{ Should conflicts ${ }^{\mathrm{a}}$} & \multicolumn{5}{|c|}{ Want conflicts ${ }^{\mathrm{b}}$} \\
\hline & \multicolumn{2}{|c|}{ Younger } & \multicolumn{2}{|c|}{ Older } & \multirow[b]{2}{*}{$F(1,60)$} & \multicolumn{2}{|c|}{ Younger } & \multicolumn{2}{|c|}{ Older } & \multirow[b]{2}{*}{$F(1,75)$} \\
\hline & $M$ & $S D$ & $M$ & $S D$ & & $M$ & $S D$ & $M$ & $S D$ & \\
\hline \multicolumn{11}{|l|}{ Source activity } \\
\hline Basic-instrumental activities & .36 & .25 & .35 & .35 & $0.03^{\dagger}$ & .61 & .20 & .64 & .31 & $0.23^{\dagger}$ \\
\hline Leisure activities & .37 & .27 & .49 & .34 & $2.30^{\dagger}$ & .08 & .08 & .18 & .24 & $7.29^{* *}$ \\
\hline Passive phases & .11 & .22 & .09 & .25 & $0.10^{\dagger}$ & .04 & .08 & .05 & .12 & $0.11^{\dagger}$ \\
\hline Social-contact activities & .12 & .14 & .07 & .13 & $1.53^{\dagger}$ & .07 & .07 & .12 & .23 & $2.01^{\dagger}$ \\
\hline Work-study-related activities & .04 & .07 & .00 & .00 & $6.57^{*}$ & .20 & .18 & .01 & .04 & $27.14^{* *}$ \\
\hline
\end{tabular}

${ }^{\mathrm{a}} F(4,57)=2.29, p>.05$, partial $\eta^{2}=.14 .{ }^{\mathrm{b}} F(5,71)=6.77, p<.01$, partial $\eta^{2}=.32$.

* $p \leq .05$. *** $p<.01$. $p>.05$. 
Table 3

What Was It That Participants Felt They Should Have Done or Would Have Wanted to Do? Proportional Within-Person Distributions of Target Activities of Should and Want Conflicts in Younger and Older Adults in Study 1

\begin{tabular}{|c|c|c|c|c|c|c|c|c|c|c|}
\hline & \multicolumn{5}{|c|}{ Should conflicts ${ }^{\mathrm{a}}$} & \multicolumn{5}{|c|}{ Want conflicts ${ }^{\mathrm{b}}$} \\
\hline & \multicolumn{2}{|c|}{ Younger } & \multicolumn{2}{|c|}{ Older } & \multirow[b]{2}{*}{$F(1,60)$} & \multicolumn{2}{|c|}{ Younger } & \multicolumn{2}{|c|}{ Older } & \multirow[b]{2}{*}{$F(1,75)$} \\
\hline & $M$ & $S D$ & $M$ & $S D$ & & $M$ & $S D$ & $M$ & $S D$ & \\
\hline \multicolumn{11}{|l|}{ Target activity } \\
\hline Basic-instrumental activities & .17 & .26 & .31 & .35 & $2.56^{\dagger}$ & .14 & .17 & .10 & .14 & $1.43^{\dagger}$ \\
\hline Leisure activities & .10 & .18 & .43 & .41 & $18.95^{* *}$ & .24 & .18 & .56 & .33 & $30.75^{* *}$ \\
\hline Passive phases & .03 & .06 & .003 & .01 & $2.25^{\dagger}$ & .38 & .20 & .28 & .33 & $2.68^{\dagger}$ \\
\hline Social-contact activities & .01 & .03 & .03 & .16 & $4.55^{*}$ & .06 & .09 & .04 & .11 & $1.09^{\dagger}$ \\
\hline Work-study-related activities & .65 & .33 & .16 & .34 & $25.93^{* *}$ & .06 & .09 & .002 & .01 & $10.86^{* *}$ \\
\hline
\end{tabular}

${ }^{\mathrm{a}} F(5,56)=8.18, p<.01$, partial $\eta^{2}=.42 . \quad{ }^{\mathrm{b}} F(5,71)=10.75, p<.01$, partial $\eta^{2}=.43$.

${ }^{*} p \leq .05 .{ }^{* * *} p<.01 . \quad{ }^{\dagger} p>.05$.

Table 4

Affective Reactivity to Motivational-Conflict Experiences in Study 1: Predicting Momentary Affect Balance Without (Model 1) and With Control (Model 2) for Within-Person Average Affect Balance

Prediction of momentary affect balance

\begin{tabular}{lcc}
\multicolumn{1}{c}{ Model parameter } & Model 1 & Model 2 \\
\cline { 2 - 3 } & & \\
Fixed effects & $0.930^{* *}$ & $1.078^{* *}$ \\
Intercept $\left(\gamma_{00}\right)$ & $0.320^{*}$ & $-0.078^{\dagger}$ \\
Age group $\left(\gamma_{01}\right)^{\mathrm{a}}$ & & $0.973^{* *}$ \\
Within-person mean affect balance $\left(\gamma_{02}\right)$ & $-0.012^{* *}$ & $-0.011^{* *}$ \\
Want conflict $\left(\gamma_{10}\right)$ & $-0.004^{\dagger}$ & $-0.003^{\dagger}$ \\
Should conflict $\left(\gamma_{20}\right)$ & $-0.010^{* * *}$ & $-0.009^{* *}$ \\
Want-and-should conflict $\left(\gamma_{30}\right)$ & $0.009^{*}$ & $0.009^{*}$ \\
Age Group $\times$ Want Conflict $\left(\gamma_{11}\right)$ & $-0.004^{\dagger}$ & $-0.004^{\dagger}$ \\
Age Group $\times$ Should Conflict $\left(\gamma_{21}\right)$ & $-0.040^{\dagger}$ & $-0.039^{\dagger}$ \\
Age Group $\times$ Want-and-Should Conflict $\left(\gamma_{31}\right)$ & & \\
Variance components & $0.363^{* *}$ & $\mathrm{~b}$ \\
Intercept $\left(u_{0 j}\right)$ & $<0.001^{*}$ & $<0.001^{*}$ \\
Want conflict $\left(u_{1 j}\right)$ & $<0.001^{*}$ & $<0.001^{\dagger}$ \\
Should conflict $\left(u_{2 j}\right)$ & $<0.001^{\dagger}$ & $<0.001^{\dagger}$ \\
Want-and-should conflict $\left(u_{3 j}\right)$ & $0.385^{* *}$ & $0.338^{* *}$ \\
SP(POW $)^{\mathrm{c}}$ & $1.264^{* *}$ & $1.183^{* *}$ \\
Residual $\left(r_{i j}\right)$ & $11.17 \%$ & $\mathrm{~b}$ \\
Modeled variance & \\
Between persons $\left(\right.$ pseudo $\left.R_{\text {Intercept }}^{2}\right)$ & $5.69 \%$ & $11.72 \%$ \\
Within persons $\left(\right.$ pseudo $\left.R_{\text {Residual }}^{2}\right)$ & \multicolumn{2}{c}{} \\
\hline
\end{tabular}

Note. Restricted maximum likelihood parameter estimates and approximate $p$ values after fitting multilevel regression models with spatial power law residual covariance structures. Motivational conflicts are reported in terms of time percentages relative to total time covered by the respective diary entry (i.e., want conflict $=$ percentage of duration of activities associated with want conflicts, should conflict $=$ percentage of duration of activities associated with should conflicts, want-and-should conflict $=$ percentage of duration of activities with simultaneously associated want-and-should conflicts). With the exception of age-group membership, all predictors are grand-mean centered. ${ }^{\mathrm{a}}$ Coding: $0=$ younger participants, $1=$ older participants. ${ }^{\mathrm{b}}$ Betweenpersons variation in intercept is completely accounted for by introducing the within-person mean of affect balance as a predictor variable. The intercept is therefore included as a fixed effect only. ${ }^{\mathrm{c}}$ Autoregressive parameter SP(POW): Estimated covariance of two adjacent diary entries in the same diary period. ${ }^{\mathrm{d}}$ Proportional reductions in variance components intercept and residual in comparison to unconditional means model (i.e., model without explanatory variables).

${ }^{*} p \leq .05 . \quad{ }^{* * *} p<.01 . \quad{ }^{\dagger} p>.05$. participants. Parameter estimates of the variance components show that significant interindividual differences remained in the average levels of affect balance and in the associations of want and of should conflicts with momentary affect balance after we controlled for age-group membership. Overall, Model 1 accounted for $11.17 \%$ of the residual between-persons variance and for $5.69 \%$ of the residual within-person variance of momentary affect balance. Comparing Model 1 with reduced model variants revealed that want conflict and simultaneous want-and-should conflict uniquely accounted for $4.00 \%$ and $0.66 \%$ of the residual within-person variance in momentary effect balance, respectively, above and beyond all other model predictors.

Next, we investigated whether the observed effects were robust when we controlled for participants' average (i.e., trait) levels of affect balance. The purpose of Model 2 was to determine whether momentary experiences of motivational conflicts predicted withinperson fluctuations of affect balance above or below the individual's average, a question that is particularly important from the individual's point of view (Reis, Sheldon, Gable, Roscoe, \& Ryan, 2000). We therefore extended Model 1 by additionally including the within-person mean of momentary affect balance across all diary entries (grand-mean centered) as the person-level predictor, thus completely accounting for between-persons variance in the intercept. Results of Model 2 (shown in the right column of Table 4) indicate that want and simultaneous want-and-should conflicts were also predictive of within-person fluctuations in affect balance below the individual's average. Overall, Model 2 accounted for $11.72 \%$ of the within-person variation of momentary affect balance (with want conflict and simultaneous want-and-should conflict uniquely accounting for $3.17 \%$ and $0.46 \%$ of the residual within-person variance, respectively, above and beyond all other model predictors).

The effects in Models 1 and 2 were robust $(p s<.05)$ when we controlled for age differences in time use, for potential trendrelated effects, and for subjective health, as tested by including the percentage of times within a diary-entry time window that the participant had spent with basic-instrumental activities, leisure activities, and work-study activities (grand-mean centered), as well as the sequential number of the diary entry (counting from zero) as additional random predictors on the diary-entry level, and 
by including participants' subjective health evaluation (grandmean centered) as an additional predictor of the random intercept.

\section{Mediation Analyses: Does Motivational Conflict in Daily Life Account for More Positive Affect Balance in Older Than in Younger Adults?}

Finally, we were interested in the question whether younger adults experienced lower average emotional well-being than older adults, in part, because affectively relevant motivationalconflict experiences (i.e., want and simultaneous want-andshould conflicts) were more prevalent in their everyday lives. To investigate this, we specified the multilevel multiplemediator model shown in Figure 3. Parameter estimates of this model resulted from four multilevel regression analyses. Model A predicted momentary affect balance using age-group membership as the single person-level predictor. Models B and C predicted percentage of durations of want and of simultaneous want-and-should conflicts, respectively, using age-group membership as the single person-level predictor. Model D predicted momentary affect balance using age-group membership as the person-level predictor and percentage of durations of want and of simultaneous want-and-should conflicts as the diary-entry level predictors. Slopes of the two diary-entry level predictors in the latter model were specified as random effects. These analyses revealed that, together, both assumed mediators accounted for $14.57 \%$ of the total age-group effect on momentary affect balance. According to the multilevel equivalent of the Sobel Test (as recommended by Krull \& MacKinnon, 2001), both specific indirect effects of age-group membership on momentary affect balance (characterizing the role of each of the proposed mediators while controlling for the other mediator) were significant (via want conflicts: $z=2.92, p<.01$; via want-and-should conflicts: $z=2.14, p<.05$ ). When we repeated these analyses while additionally controlling for age

\section{A. Multilevel Total Effect Model:}

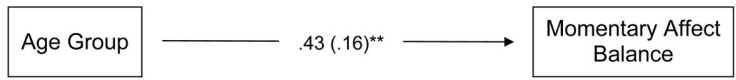

B. Multilevel Multiple Mediator Model:

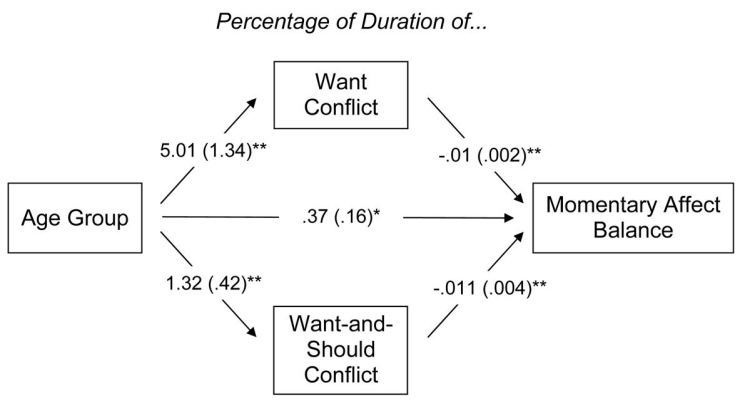

Figure 3. Study 1: Multilevel mediation. Path coefficients are unstandardized parameter estimates (standard errors in parentheses) from multilevel regressions. ${ }^{*} p<.05$. ${ }^{* *} p<.01$. differences in time use, for potential trend-related effects and for subjective health, we yielded the same pattern of results (both specific indirect effects: $p<.05$ ).

Overall, and bearing in mind that correlational data do not allow conclusions about causality, the obtained pattern of findings can be interpreted as being consistent with the assumption that experiences of want and simultaneous want-and-should conflicts are among the processes that underlie the age-group difference in average affect balance.

\section{Study 2}

Study 2 had two aims. One was to replicate the findings from Study 1 in another sample. The other was to extend and complement Study 1 in several respects: Whereas we had contrasted younger and older adults in Study 1, we recruited an ageheterogeneous sample covering the adult lifespan from early, via middle, to later adulthood for Study 2. Furthermore, in Study 1, we had investigated a selective sample of predominantly female exercise beginners. In Study 2, we attempted to decrease sampling bias by working with a survey company to recruit a sample that was carefully stratified by age, gender, and education. In addition, in Study 1, we used a diary method, where the advantage of obtaining comprehensive reports of participants' waking days comes at the potential cost of retrospective memory biases when thinking back over the past 4-6 hr. Therefore, in Study 2, we used experience sampling, thus obtaining snapshots of participants' momentary experiences. Finally, in Study 2 we extended our research approach by investigating two additional context characteristics-dealing with obstacles and goal mindedness - that might be associated with the occurrence of motivational-conflict experiences.

\section{Method}

\section{Participants}

The sample comprised 63 participants ranging in age from 20.7 to 69.4 years $(M=44.8, S D=14.0)$. About equal numbers of participants belonged to each of five age decades (20-29 years: $n=13 ; 30-39$ years: $n=12 ; 40-49$ years: $n=11 ; 50-59$ years: $n=15 ; 60-69$ years: $n=12$ ). Within each age decade, the sample was approximately stratified by gender (total sample: $47.6 \%$ men, $52.4 \%$ women) and education (total sample, male participants: $50.0 \%$ with 12 or more years of education; total sample, female participants: $51.5 \%$ with 12 or more years of education). Recruitment was accomplished with the help of a survey company that recruited Berlin residents by means of a stratified random dialing procedure. Participants were recruited on a first-come basis until prescribed cell sizes of the sample composition were reached.

Thirty participants $(47.7 \%)$ worked full or part time, 10 participants $(15.9 \%)$ were unemployed, 5 participants $(7.9 \%)$ were in training (university or vocational training), 12 participants (19.0\%) had retired, 3 participants $(4.8 \%)$ were homemakers, and 3 participants $(4.8 \%)$ specified their current occupation as "other."

\section{Procedure}

The study started with an instruction session in which participants received an experience-sampling device (Palm [Sunnyvale, CA] 
m500 personal data assistant [PDA]). Each PDA was equipped with a testing program that had been developed for our study. ${ }^{3}$ Participants carried the PDA with them at all times during three experiencesampling periods of 3 consecutive days. The three experiencesampling periods together covered 6 weekdays (Monday-Friday) and 3 weekend days (Saturday or Sunday) and were separated by intervals of 6 days. On each experience-sampling day, the PDA signaled participants 6 times to complete a questionnaire that had opened on the screen and that referred to their momentary situation and experiences. Measurement occasions were distributed throughout a time window of $12 \mathrm{hr}$, the beginning of which was chosen by the participants according to their personal waking habits. During each of six 2-hr time periods within the participant's personal time window, one signal was scheduled randomly, with the provision that two adjacent measurement occasions were at least 10 min apart. If participants did not respond, they were reminded twice by auditory signals, occurring after 5 and after $10 \mathrm{~min}$. If there was still no response, the questionnaire closed after $15 \mathrm{~min}$, thus reducing participants' degree of freedom in determining when to complete the questionnaire. To obtain a sufficient number of measurement occasions, we prolonged each of the 3-day experience-sampling periods for a day if participants completed less than five of the six daily measurements (up to three additional experience-sampling days per period). Fourteen participants $(22.2 \%)$ were given an assessment prolongation of 1 day; 6 participants $(9.5 \%)$ were given prolongations of 2 days; and 1 participant each (1.6\%) was given a prolongation of 4, 5, and 6 days, respectively. No participant dropped out. On average, participants completed 54.33 measurement occasions ( $S D=3.96$, range: 44 to 75 measurement occasions). They were reimbursed $€ 110$ (approximately US\$130).

Whenever a beep signaled the beginning of a measurement occasion, a screen opened on the PDA that instructed participants to respond to the subsequent questions with respect to their momentary experiences. Items concerning the present research are described below. Participants further responded to some other questions that are not relevant in the present context.

\section{Instruments}

Current affect balance. As in Study 1, we used the short (i.e., 12-item) version of the Multidimensional Affect Rating Scale (Steyer et al., 1997). Participants indicated how much they currently experienced each emotion using a scale ranging from 1 (not at all) to 5 (very much). Again, the Positive and Negative Affect scores correlated substantially (average within-person $r=-.76, S D=.14$ ). For reasons of parsimony, and because Positive and Negative Affect scores did not yield differential results, we again report an aggregated affectbalance score, obtained by subtracting the average response to the six items with negative valence (average within-person $M=1.85, S D=$ 0.48 ) from the average response to the six items with positive valence (average within-person $M=3.53, S D=0.46$ ). The within-person Cronbach's alpha of this aggregate measure across days was $M=.87$ $(S D=.07)$.

Current activity. Participants responded to the question "What did you do when the signal occurred?" by choosing among eight response options the one that best described their current main activity: (a) working-studying $(M=20.11 \%, S D=13.87)$, (b) doing the chores $(M=11.40 \%, S D=7.07)$, (c) hobby/leisure activity $(M=14.60 \%, S D=11.59)$, (d) doing nothing-sleeping
$(M=8.21 \%, S D=5.95)$, (e) reading-watching $T V(M=13.61 \%$, $S D=10.15)$, (f) conversation-visit $(M=14.68 \%, S D=8.66)$, and $(\mathrm{g})$ other $(M=17.39 \%, S D=10.24){ }^{4}$

Momentary motivational conflict. Two items assessed current intensities of want and should conflicts: (a) "Would you have liked to do something else instead?" and (b) "Should you have done something else instead?" Participants responded to both items on a scale ranging from 1 (not at all) to 5 (very much; want: $M=2.05$, $S D=0.52$; should: $M=1.86, S D=0.57$ ). All participants reported occurrences of want and should conflicts (i.e., at least one occasion with response $>1)^{5}$

Overcoming obstacles. Participants agreed to (or disagreed with) the statement "At the moment of the signal, I was working on overcoming obstacles" on a binary response scale (affirmative responses: $M=25.07 \%, S D=15.56){ }^{6}$

Goal-mindedness. Participants also agreed to (or disagreed with) the statement "At the moment of the signal, I had an explicit goal in mind and was pursuing it" on a binary response scale (affirmative responses: $M=55.26 \%, S D=20.16$ ). ${ }^{7}$

Explorations of time-related trends. There were quadratic trends in affect balance, should-conflict, and want-conflict intensity, accounting for $5.57 \%, 2.74 \%$, and $2.20 \%$ of the within-person residual variance, respectively. To control for the observed timerelated trends, we included the observation number and the squared observation number (counting from zero) as control variables in all analyses. ${ }^{8}$

\section{Results}

\section{Contexts of Motivational-Conflict Experiences in Day-to-Day Life}

In a first series of analyses, we were interested in the everyday life contexts associated with motivational conflicts. In the exten-

\footnotetext{
${ }^{3}$ The testing software was a dialogue-based C-program that controlled the participants' assessment schedule, presented items, and recorded responses. Participants navigated the questionnaire using the PDA's touchscreen functionality.

${ }^{4}$ Descriptives are from the distribution of within-person percentages.

${ }^{5}$ Descriptives are from the distribution of within-person percentages.

${ }^{6}$ Descriptives are from the distribution of within-person percentages.

${ }^{7}$ Descriptives are from the distribution of within-person percentages.

${ }^{8}$ Using the same multilevel-regression approach as in Study 1, we examined the presence of time-related trends in the central study variables. That is, we ran no-change, linear-change, and quadratic-change models in the predictions of momentary affect balance, momentary want-conflict intensity, and momentary should-conflict intensity. For all three dependent variables, likelihood ratio tests on the change in deviance revealed that quadratic-change models fitted the data best ( $p$ s $<.01$ ), accounting for $5.57 \%, 2.74 \%$, and $2.20 \%$ of the within-person residual variance in affect balance, should-conflict, and want-conflict intensity, respectively. Parameter estimates indicated an average initial improvement in affect balance that slowed down with time and then reversed, on average, at about the 39th measurement occasion. Similarly, parameter estimates in the predictions of should and want conflicts indicated initial declines in reported conflict intensities, which slowed down with time and reversed at about the 33rd and 34th measurement occasion, respectively (calculation of turning points after Singer \& Willet, 2003). We further explored potential age-group differences in these quadratic-trend models. There were none (i.e., interactions with age group were not significant, $p \mathrm{~s}>.05$ ).
} 
sion of Study 1, we investigated the respective roles of current goal mindedness (i.e., having an explicit goal in mind and pursuing it) and working on overcoming obstacles. As in Study 1, we used SAS PROC MIXED and restricted maximum likelihood to run multilevel regression models fitting the spatial power law residual covariance structure (this time referencing time in study as minutes elapsed since 00:00 a.m. of the first experiencesampling day).

We predicted momentary want- and should-conflict intensities using the following independent variables: currently working on overcoming obstacles $(0=$ no, $1=$ yes $)$, current goal mindedness $(0=$ no, $1=$ yes $)$, as well as number and squared number of the current experience-sampling occasion (counting from zero). We assumed intercept and slopes to vary across individuals. The results shown in the left column of Table 5 indicate that participants experienced higher intensities of momentary want conflicts when they worked on overcoming obstacles than when they did not, and when they were pursuing an explicit goal. Parameter estimates of the variance components indicate significant interindividual differences in the average intensity of want conflicts and in the effects of current obstacle and current goal mindedness. Overall, the model accounted for $11.86 \%$ of the residual withinperson variance of momentary want-conflict intensity. Comparing the full model with reduced model variants revealed that currently working on overcoming obstacles and current goal mindedness uniquely accounted for $5.70 \%$ and $2.05 \%$ of the residual withinperson variance in momentary want-conflict intensity above and beyond all other model predictors, respectively.

Table 5

Everyday Contexts of Motivational-Conflict Experiences in Study 2: Predicting Momentary Intensities of Want and Should Conflicts

\begin{tabular}{|c|c|c|}
\hline \multirow[b]{2}{*}{ Model parameter } & \multicolumn{2}{|c|}{$\begin{array}{l}\text { Prediction of current } \\
\text { conflict intensity }\end{array}$} \\
\hline & Want & Should \\
\hline \multicolumn{3}{|l|}{ Fixed effects } \\
\hline Intercept $\left(\gamma_{00}\right)$ & $1.98^{* * *}$ & 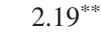 \\
\hline Current obstacle $\left(\gamma_{10}\right)^{\mathrm{a}}$ & $0.60^{* *}$ & $0.03^{\dagger}$ \\
\hline Current goal-mindedness $\left(\gamma_{20}\right)^{\mathrm{a}}$ & $0.20^{* * *}$ & $-0.24^{\text {*** }}$ \\
\hline Occasion number $\left(\gamma_{30}\right)^{\mathrm{b}}$ & $-0.01^{*}$ & $-0.02^{* *}$ \\
\hline Squared occasion number $\left(\gamma_{40}\right)^{\mathrm{b}}$ & $<0.01^{*}$ & $<0.01^{* *}$ \\
\hline \multicolumn{3}{|l|}{ Variance components } \\
\hline Intercept $\left(u_{0 j}\right)$ & $0.09^{* *}$ & $0.34^{* * *}$ \\
\hline Current obstacle $\left(u_{1 j}\right)$ & $0.23^{* *}$ & $0.15^{\text {** }}$ \\
\hline Current goal mindedness $\left(u_{2 j}\right)$ & $0.15^{* *}$ & $0.09^{*}$ \\
\hline Occasion number $\left(u_{3 j}\right)$ & $<0.01^{* * *}$ & $<0.01^{* *}$ \\
\hline $\mathrm{SP}(\mathrm{POW})^{\mathrm{c}}$ & $0.98^{* * *}$ & $0.98^{\text {*** }}$ \\
\hline Residual $\left(r_{i j}\right)$ & $1.47^{* *}$ & $1.09^{\text {** }}$ \\
\hline \multicolumn{3}{|l|}{ Modeled variance ${ }^{\mathrm{d}}$} \\
\hline Within persons (pseudo $R_{\text {Residual }}^{2}$ ) & $11.86 \%$ & $8.31 \%$ \\
\hline
\end{tabular}

Note. Restricted maximum likelihood parameter estimates and approximate $p$ values after fitting multilevel regression models with spatial power law residual covariance structures.

${ }^{\text {a }}$ Dummy coding: $0=$ no, 1 = yes. ${ }^{\mathrm{b}}$ Counting from zero. ${ }^{\mathrm{c}}$ Autoregressive parameter SP(POW): Estimated covariance of two adjacent measurements taken $1 \mathrm{~min}$ apart. ${ }^{\mathrm{d}}$ Proportional reductions in variance component residual in comparison to unconditional means model (i.e., model without explanatory variables).

${ }^{*} p \leq .05 .{ }^{* * *} p<.01 .{ }^{\dagger} p>.05$.
The results presented in the right column of Table 5 indicate that participants experienced lower intensities of should conflicts when they were currently pursuing a specific goal, while the effect of current obstacle was not significantly different from zero. Inspection of the variance components indicate significant interindividual differences in the average intensity of should conflicts and in the effects of obstacle and goal mindedness. Overall, the model accounted for $8.31 \%$ of the residual within-person variance of momentary should-conflict intensity. Comparing the full model with reduced model variants revealed that current goal mindedness uniquely accounted for $2.12 \%$ of the residual within-person variance in momentary should-conflict intensity above and beyond all other model predictors.

In a next step, we investigated whether the observed context effects were moderated by participants' age. With this aim, we extended the models shown in Table 3 by including participants' age (grand-mean centered) as a person-level predictor of the random intercept and slopes. In the prediction of momentary wantconflict intensity, all effects, including the intercept (i.e., average want-conflict intensity when all other predictors are zero), were independent of age $(p \mathrm{~s}>.05)$. The same was true in the prediction of momentary should-conflict intensity.

While these analyses suggested weak or no associations between age and the average intensities of want and should conflicts, additional analyses of the configuration of want and should conflicts revealed the expected pronounced age effects, and particularly an age-related increase in the relative frequency of situations where participants experienced neither want nor should conflicts. These analyses are described next.

\section{Age-Related Differences in the Configuration of Motivational-Conflict Experiences}

We first determined, separately for each participant, the withinperson correlation of want-conflict and should-conflict intensities This within-person correlation was significantly associated with participants' age $(r=.39, p=.001)$, indicating age-related differences in the configuration of motivational-conflict occurrences in daily life.

To follow up on this finding, we next determined the correlations between participants' age and the within-person percentages of four types of motivational-conflict configurations: (a) percentage of assessment occasions with neither want nor should conflict present, (b) percentage of occasions with only want conflict present (i.e., want conflict $>1$, should conflict $=1$ ), (c) percentage of occasions with only should conflict present (i.e., want conflict $=1$, should conflict $>1$ ), and (d) percentage of occasions with both want and should conflicts present (i.e., want and should conflict $>1$ ). Consistent with Study 1, Study 2 revealed that the older participants were, the more frequently they reported that neither want nor should conflicts were present $\left(r_{\text {age }}-\right.$ percentage of neither conflict $=$ $.32, p=.01)$ and the less frequently they reported the presence of pure want conflicts $\left(r_{\text {age }}-\right.$ percentage of only want $\left.=-.24, p=.06\right)$ and of pure should conflicts $\left(r_{\text {age }}-\right.$ percentage of only should $\left.=-.28, p=.03\right)$. Participants' age was unrelated to the percentage of measurement occasions when simultaneous want-and-should conflicts were reported $\left(r_{\text {age }}-\right.$ percentage of want and should $\left.=-.06, p>.10\right)$. Figure 4 illustrates these age associations by depicting the average withinperson percentage of occurrences of the four motivational-conflict 


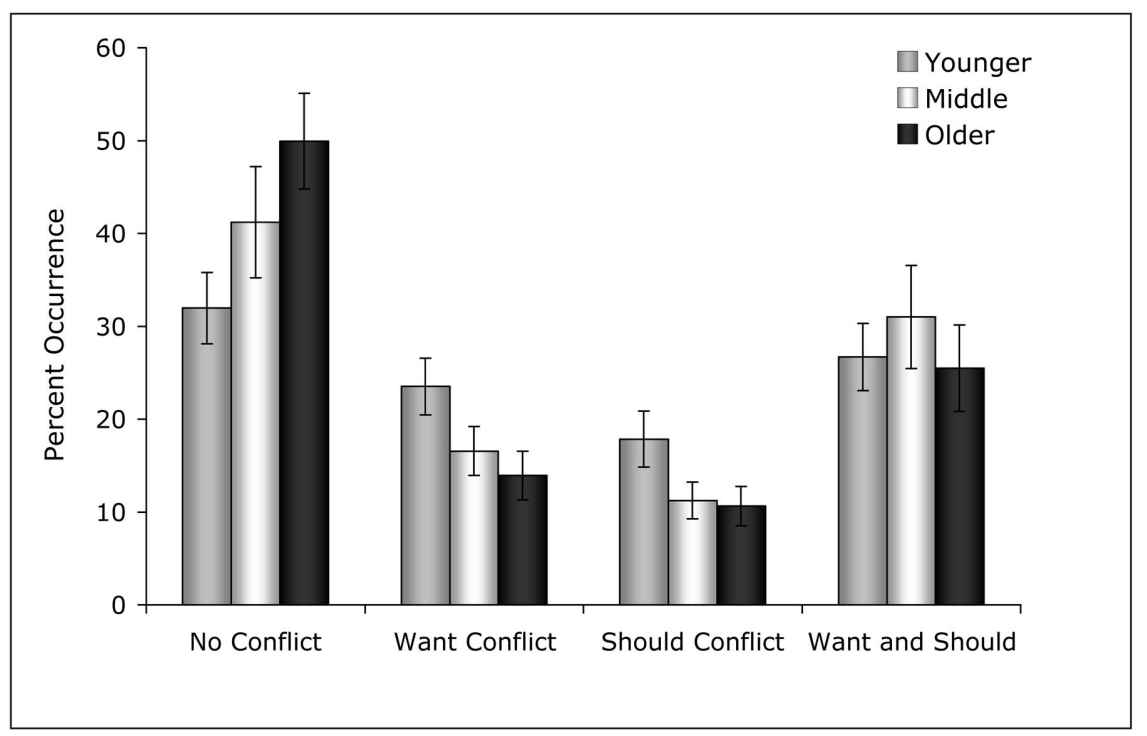

Figure 4. Study 2: Age-group differences in percentage of experience samples without and with reports of want, should, and simultaneous want-and should conflicts. Error bars represent two standard errors of the mean.

configurations in three equally large age groups (younger: $20.72-$ 37.67 years, $M=28.82, n=21$; middle: $37.96-52.63$ years, $M=$ 45.32, $n=21$; older: $52.92-69.43$ years, $M=60.22, n=21)$. As in Study 1, the age effects in motivational conflicts were independent of whether assessments were obtained during the week or during weekends (when sociostructural constraints for working adults are presumably weaker).

Overall, and in agreement with Study 1, these findings demonstrate an age-related decrease in the prevalence of motivationalconflict experiences in everyday life, resulting in an age-related increase in the proportion of daily-life situations where participants did not experience any motivational conflict at all. This finding could not be accounted for by differences in everyday-life contexts. That is, the correlation between age and the proportion of daily-life situations where participants did not experience any motivational conflict at all remained significant after we controlled for interindividual differences in the percentage of goalmindedness and obstacles (partial $r=.25, p<.05$ ) and after we controlled for interindividual differences in the percentage of different everyday-activity types (partial $r=.27, p<.05$ ).

\section{Age-Related Differences in Everyday Affect Balance}

In order to investigate whether age-related differences in everyday affect balance could also be replicated at the experiencesampling level, we predicted participants' momentary affect balance using occasion number and squared occasion number (counting from zero) as predictors, thus controlling for trendrelated influences. Intercept and slopes were assumed to vary across individuals. On the person level, we expressed the random intercept by introducing participants' age (grand-mean centered) as a person-level predictor. Replicating findings from Study 1, results indicated that participants tended, on average, to experience more intense positive than negative affect (i.e., fixed intercept $\left.\gamma_{\mathrm{oO}}=1.43, p<.01\right)$ and that this positive affect balance was more pronounced the older participants were (i.e., fixed effect of age $\left.\gamma_{01}=0.02, p<.05\right)$. Overall, the model accounted for $2.49 \%$ of the between-persons residual variance (entirely due to age) and for $5.53 \%$ of the within-person residual variance (entirely due to the trend parameters).

\section{Affective Reactivity to Everyday Motivational- Conflict Configurations}

Following the same rationale as in Study 1, we next ran multilevel models investigating participants' affective reactivity to different configurations of everyday motivational-conflict experiences. At the experience-sampling level, we predicted participants' momentary affect balance using motivational-conflict configuration (dummy coded, with "neither want nor should conflict" as the comparison group), occasion number, and squared occasion number (i.e., linear and quadratic trend, counting from zero) as independent variables. We assumed intercept and slopes to vary across individuals. On the person level, we expressed the random intercept and the random slopes of the motivational-conflict dummy variables by introducing age (grand-mean centered) as a personlevel predictor. Parameter estimates of the resulting multilevel model are summarized in the left column of Table 6. With one exception, the interpretation of parameter estimates follows the logic described above. The exception pertains to the slopes of the dummy codes of motivational-conflict configuration, which indicate the momentary affect balance accompanying a given configuration of want and should conflicts as opposed to situations where neither want nor should conflicts are present, under the assumption that all other model predictors are zero.

Results indicate that the presence of all three motivationalconflict configurations-simultaneous want-and-should conflicts, pure want conflicts, and pure should conflicts-were associated with impairments in affect balance when compared to conflict-free situations. Inspection of the interaction terms 
Table 6

Affective Reactivity to Motivational-Conflict Experiences in Study 2: Predicting Momentary Affect Balance Without (Model 1) and With Control (Model 2) for Within-Person Average Affect Balance

\begin{tabular}{|c|c|c|}
\hline \multirow[b]{2}{*}{ Model parameter } & \multicolumn{2}{|c|}{$\begin{array}{c}\text { Prediction of momentary } \\
\text { affect balance }\end{array}$} \\
\hline & Model 1 & Model 2 \\
\hline \multicolumn{3}{|l|}{ Fixed effects } \\
\hline Intercept $\left(\gamma_{00}\right)$ & $1.97^{* * *}$ & $1.93^{\text {*** }}$ \\
\hline Age $\left(\gamma_{01}\right)^{\mathrm{a}}$ & $0.02^{*}$ & $0.003^{+}$ \\
\hline Within-person mean affect balance $\left(\gamma_{02}\right)^{\mathrm{a}}$ & & $0.86^{* *}$ \\
\hline \multicolumn{3}{|l|}{ Conflict configuration ${ }^{\mathrm{b}}$} \\
\hline Want-and-should conflict $\left(\gamma_{10}\right)$ & $-0.93^{* * *}$ & $0.85^{\text {*** }}$ \\
\hline Want conflict $\left(\gamma_{20}\right)$ & $-0.85^{* *}$ & $0.81^{\text {*** }}$ \\
\hline Should conflict $\left(\gamma_{30}\right)$ & $-0.23^{* *}$ & $0.18^{* * *}$ \\
\hline Age $\times$ Want-and-Should Conflict $\left(\gamma_{11}\right)$ & $-0.02^{* * *}$ & $-0.01^{* *}$ \\
\hline Age $\times$ Want Conflict $\left(\gamma_{21}\right)$ & $<0.01^{\dagger}$ & $<0.01^{\dagger}$ \\
\hline Age $\times$ Should Conflict $\left(\gamma_{31}\right)$ & $-0.01^{\dagger}$ & $-0.01^{\dagger}$ \\
\hline Occasion number $\left(\gamma_{40}\right)^{\mathrm{c}}$ & $0.02^{* * *}$ & $0.02^{*}$ \\
\hline Squared occasion number $\left(\gamma_{50}\right)^{\mathrm{c}}$ & $<-0.01^{* *}$ & $<-0.01^{*}$ \\
\hline \multicolumn{3}{|l|}{ Variance components } \\
\hline Intercept $\left(u_{0 j}\right)$ & $0.46^{* * *}$ & d \\
\hline \multicolumn{3}{|l|}{ Conflict configuration } \\
\hline Want-and-should conflict $\left(u_{1 j}\right)$ & $0.18^{* *}$ & $0.12^{\text {*** }}$ \\
\hline Want conflict $\left(u_{2 j}\right)$ & $0.13^{* *}$ & $0.08^{*}$ \\
\hline Should conflict $\left(u_{3 j}\right)$ & $0.00^{\dagger}$ & $0.00^{\dagger}$ \\
\hline Occasion number $\left(u_{4 j}\right)$ & $<0.01^{* *}$ & $<0.01^{\dagger}$ \\
\hline $\mathrm{SP}(\mathrm{POW})^{\mathrm{e}}$ & $0.99^{* *}$ & $0.99^{* * *}$ \\
\hline & $1.16^{* *}$ & $1.20^{\text {*** }}$ \\
\hline \multicolumn{3}{|l|}{ Modeled variance $\mathrm{f}^{\mathrm{f}}$} \\
\hline Between persons (pseudo $R_{\text {Intercept }}^{2}$ ) & $27.88 \%$ & d \\
\hline Within persons (pseudo $R_{\text {Intercept }}^{2}$ ) & $22.70 \%$ & 19.78 \\
\hline
\end{tabular}

Note. Restricted maximum likelihood parameter estimates and approximate $p$ values after fitting multilevel regression models with spatial power law residual covariance structures.

${ }^{a}$ Grand-mean centered. ${ }^{\mathrm{b}}$ Dummy coding with comparison group: neither want nor should conflict. ${ }^{\mathrm{c}}$ Counting from zero. ${ }^{\mathrm{d}}$ Between-persons variation in intercept is completely accounted for by introducing the within-person mean of affect balance as a predictor variable. The intercept is therefore included as a fixed effect only. ${ }^{\mathrm{e}}$ Autoregressive parameter SP(POW): Estimated covariance of two adjacent measurements taken 1 min apart. ${ }^{\mathrm{f}}$ Proportional reductions in variance components intercept and residual in comparison to unconditional means model (i.e., model without explanatory variables).

${ }^{*} p \leq .05 .{ }^{* * *} p<.01 .{ }^{\dagger} p>.05$.

reveals that the affective reactivity to either want or should conflicts was independent of participants' age but that there was an age-related increase in the affective reactivity to simultaneous want-and-should conflicts.

Parameter estimates of the variance components indicate significant interindividual differences in the average levels of affect balance as well as in the slopes of all independent variables with the exception of the dummy code for should conflicts. Overall, Model 1 accounted for $27.88 \%$ of the residual between-persons variance and for $22.70 \%$ of the residual within-person variance of momentary affect balance. Comparing Model 1 with a reduced model variant revealed that $25.39 \%$ of between-persons and $17.17 \%$ of within-person residual variance were uniquely accounted for by the dummy codes for motivational-conflict configurations and their respective age interactions.
Next, we investigated whether the observed effects were robust when we controlled for participants' average levels of affect balance, which we included as an additional person-level predictor of the random intercept (see right column of Table 6). Consistent with the results in Study 1, motivational conflict was not only predictive of lower absolute levels of momentary affect balance but also of within-person fluctuations in affect balance below the individual's average. Overall, Model 2 accounted for $19.78 \%$ of the withinperson variation of momentary affect balance.

Finally, we investigated whether the effects in Models 1 and 2 were robust to controlling for current activity (effect coding of seven activity types), current goal mindedness (dummy coded), and currently working on overcoming obstacles (dummy coded). Slopes of these control variables were allowed to vary across individuals. All effects of Models 1 and 2 remained significant in these control analyses $(p \mathrm{~s}<.01)$.

\section{Mediation Analyses: Does Age-Related Decrease in Motivational-Conflict Prevalence Account for Age-Related Increase in Positive Affect Balance?}

In Study 1, age-group differences in the prevalence of motivational-conflict experiences partially mediated the age-group difference in day-to-day emotional well-being. To investigate whether this finding could be replicated in Study 2, we specified the multilevel mediator model shown in Figure 5. On the basis of the pattern of findings reported above, we used a dichotomous mediator variable in this model that characterizes each assessment occasion in terms of the absence or presence of motivational conflicts (i.e., $0=$ no conflict present; $1=$ want and/or should conflict present).

Parameter estimates of the multilevel mediator model in Figure 5 resulted from three multilevel regression analyses, predicting momentary affect balance (Model A) and presence-absence of motivational conflicts (Model B) using age as a person-level predictor, and predicting momentary affect balance using age as a

\section{A. Multilevel Total Effect Model:}

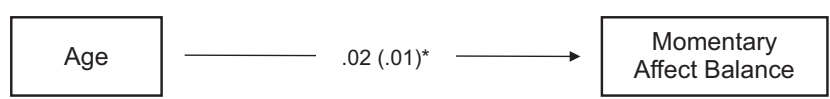

B. Multilevel Mediator Model:

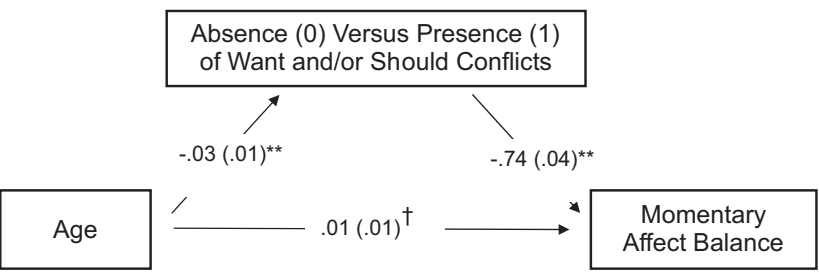

Figure 5. Study 2: Multilevel mediation. Path coefficients are unstandardized parameter estimates (standard errors in parentheses) from multilevel regressions (age effect on mediator from multilevel logistic regression) that control for linear and quadratic trend. ${ }^{\dagger} p>.05 .{ }^{*} p<$ .05. ${ }^{* * *} p<.01$. 
person-level predictor and presence-absence of motivational conflicts as an experience-sampling level predictor (Model C). Linear and quadratic trends were included as control variables in all three models. Slopes of motivational conflict and linear trend were specified as random effects. Models $\mathrm{A}$ and $\mathrm{C}$ were estimated in SAS PROC MIXED. We specified Model B as a multilevel logistic regression model and estimated in SAS NLMIXED, using the macro provided by Van Ness, O'Leary, Byers, Fried, and Dubin (2004). ${ }^{9}$

Together, these analyses revealed that the presence or absence of motivational conflicts as a mediator accounted for $24.35 \%$ of the total age effect on momentary affect balance. This mediation effect was significant according to the multilevel equivalent of the Sobel Test (as recommended by Krull \& MacKinnon, 2001; $z=$ $2.80, p<.01)$ and robust to additionally controlling for current activity, current goal mindedness, and current coping with obstacles $(z=2.60, p<.01)$.

\section{General Discussion}

The present research was guided by the question which role day-to-day motivational-conflict experiences-experiencing that one wants to and/or should do something other than what one is doing - plays in everyday emotional well-being across adulthood. Specifically, we addressed three interrelated research questions: (a) Are there differences in the frequency of want and should conflicts in the daily lives of adults of various ages? (b) In which internal and external contexts do day-to-day motivational conflicts occur? (c) Do age-related differences in the frequency of motivational conflict account for age differences in day-to-day emotional well-being?

We took two complementary approaches to investigate these questions. In Study 1, younger and older adults kept comprehensive activity diaries spanning their entire waking day. In Study 2, we investigated an age-heterogeneous sample covering the entire adult lifespan. In Study 2, we minimized retrospective response bias by using experience sampling. Below, we discuss the results of both studies referring to the three central research questions that guided our investigations.

\section{Fewer Day-to-Day Motivational Conflicts in Older Adulthood}

The results from both studies confirmed the expectation that older adults experience fewer motivational conflicts in their everyday lives than younger and middle-aged adults. These age effects were robust when we controlled for potential effects of time (i.e., how often participants had already responded to the conflictrelated questions) and for subjective health. Interestingly, age differences in conflict experience also could not be attributed to the fact that the pattern of involvement in everyday activities differed between adults of different ages (e.g., that older adults had more spare time for leisure activities, whereas younger adults were more involved in work or study-related activities).

Why, then, are day-to-day motivational conflicts less prevalent in older adults? We had hypothesized that increasing behavioral selectivity and decreasing sociocultural constraints could be among the mediating mechanisms. However, these expectations were not confirmed. In Study 1, older adults did show a higher behavioral selectivity than younger adults (i.e., they engaged in fewer types of different activities within a circumscribed time window), but behavioral selectivity was unrelated to the occurrence of motivational conflicts. Also, age differences in motivational conflicts in both studies occurred irrespectively of whether assessments were obtained during the week or during weekends (when sociostructural constraints for working people are presumably weaker).

Our respective hypotheses had been based on the assumption that older adults encounter fewer motivational conflicts in their daily lives than do younger adults. In other words, we supposed that older adults confront fewer situations in which they have competing motivational impulses and are forced to prioritize one over the other. Another possibility is that older adults come to terms with motivational-conflict situations more quickly. Consistent with empirical evidence showing an age-related increase in the flexibility of withdrawing from unattainable goals (e.g., Brandtstädter \& Renner, 1990; Wrosch, Heckhausen, \& Lachman, 2000), one could speculate that older adults find it easier than their younger counterparts to give up a behavioral tendency when it conflicts with another one, resulting in a less intense and less lasting experience of motivational conflict. This could result from their lifelong experience with encountering and mastering intraindividual conflicts. In fact, such an interpretation is consistent with theoretical claims in developmental psychology arguing that the acknowledgement, confrontation, and eventual solution of intraindividual conflict provide important impulses for developmental progress (e.g., Brim \& Kagan, 1980). Future research will need to combine well-controlled experimental paradigms and fine-grained process analyses with long-term longitudinal designs to investigate these possibilities. Another interesting question for future research is to investigate potential age-related differences in the proneness to make specific behavioral choices once motivational-conflict situations are encountered (i.e., people's tendency to prioritize want or should tendencies over each other).

\section{Contexts of Day-to-Day Motivational Conflicts}

The present research identified three characteristics of people's everyday life contexts that are associated with the prevalence of motivational-conflict experiences. An important concomitant of both want and should conflicts is the type of activity people engage in. In Study 1, we found for younger and older adults that should conflicts occurred most frequently when participants engaged in leisure and in basic-instrumental activities, while want conflicts

\footnotetext{
${ }^{9}$ Procedures available for estimating multilevel logistic regressions generally have limited capacities for modeling the covariance structure of correlated data. Model B is thus insofar an exception to all other multilevel models reported in this article as it does not specify the spatial power residual covariance structure to accommodate the unequally spaced repeated measures design. Reestimating Model B as a linear-probability model specifying the spatial power residual covariance structure in SAS PROC MIXED, however, yielded the same pattern of findings (i.e., significant mediation effect according to the multilevel equivalent of Sobel Test: $z=2.69, p=.005$ ). Note that Li, Schneider, and Bennett (2007) have shown that linear-probability estimates provide a good approximation of the mediation effect of binary mediators when the distribution of the independent variable (i.e., age) is symmetric, as is the case in Model B.
} 
occurred most frequently when participants engaged in basicinstrumental activities. When should conflicts were present, younger adults most frequently reported that they should be engaged in work-study-related activities rather than in what they were currently doing, whereas older adults most frequently reported that they should rather be engaged in leisure or basicinstrumental activities. When want conflicts were present, both younger and older adults most frequently reported that they would rather be passive or engage in leisure activities than in what they were currently doing.

In addition, Study 2 showed, that being currently focused on the pursuit of an explicit goal was associated with a higher intensity of want conflicts but a lower intensity of should conflicts. This was true irrespective of age. In addition, and again unrelated to age, currently working on overcoming obstacles was associated with a higher intensity of want conflicts. These findings support the assumption that motivational conflicts occur within specific internal (i.e., goal mindedness) and external contexts (i.e., presence of obstacles). Interestingly, however, these contextual factors did not account for the observed age-related differences in motivationalconflict prevalence.

\section{Motivational Conflicts Mediate Age Differences in Emotional Well-Being}

In line with the mounting evidence suggesting positive agerelated trajectories of emotional well-being, both studies showed that age was positively related to average day-to-day emotional well-being. Both studies also support the hypothesis that day-today motivational conflict experiences are accompanied by impaired emotional well-being. Moreover, age-related differences in the frequency of day-to-day motivational conflicts mediated the positive age difference in affect balance. These findings complement the currently prevailing focus on resilience despite major loss or challenge as a mediating mechanism underlying positive adult trajectories in emotional well-being (for a review, see Staudinger, 2000) by demonstrating the respective role of everyday life experiences. Although definite conclusions regarding causality are not possible with correlational data, the pattern of findings is in line with the view that an age-related decrease in motivational-conflict experiences may be among the processes underlying an age-related improvement in day-to-day emotional well-being.

\section{Limitations}

An important limitation of this research is its cross-sectional design. Long-term longitudinal investigations will be necessary to determine whether the age-related differences observed in the present studies correspond to intraindividual change as people age. Furthermore, our findings are based on samples covering adulthood from about 20 to about 70 years. Future research is needed to investigate the generalizability of the findings to other age groups, such as very old adults. Another limitation of this research is its correlational nature. While we assume that motivational conflicts are antecedents of emotional well-being, conclusions about causality are not possible with the data available. Future researchers will need to use well-controlled experiments to overcome this limitation. Furthermore, we only investigated a selection of potentially relevant contextual factors influencing the experience of day-to-day motivational conflicts. Other potentially important factors, such as objective health and socioeconomic status, were not considered. Finally, the exclusive reliance on self-report limited the present research to the investigation of consciously accessible aspects of experiences, while not consciously accessible aspects could not be assessed. In addition, self-reports might be limited in their accuracy, due to, for example, self-deceptive processes (Sackeim, 1983). An intriguing quest for future research therefore is the implementation of objective and indirect assessment methods.

\section{Conclusion}

This research demonstrates that studying experiences in people's daily lives, in addition to focusing on major events, helps to understand the trajectory of emotional well-being throughout adulthood. Momentary experiences of want and should conflicts are among the day-to-day experiences that influence people's emotional well-being. The presented findings suggest that an agerelated decrease in the frequency of day-to-day motivationalconflict experiences may be among the factors that contribute to a positive age trajectory of everyday emotional well-being.

\section{References}

Allen, T. D., Herst, D. E. L., Bruck, C. S., \& Sutton, M. (2000). Consequences associated with work-to-family conflict: A review and agenda for future research. Journal of Occupational Health Psychology, 5, 278-308.

Bagozzi, R. P., Baumgartner, H., \& Pieters, R. (1998). Goal-directed emotions. Cognition and Emotion, 12, 1-26.

Bazerman, M. H., Tenbrunsel, A. E., \& Wade-Benzoni, K. A. (1998). Negotiating with yourself and losing: Making decisions with competing internal preferences. Academy of Management Review, 23, 225-241.

Birditt, K. S., \& Fingerman, K. L. (2003). Age and gender differences in adults' descriptions of emotional reactions to interpersonal problems. Journals of Gerontology, Series B: Psychological Sciences, 58, P237-P245.

Brandtstädter, J., \& Renner, G. (1990). Tenacious goal pursuit and flexible goal adjustment: Explication and age-related analysis of assimilative and accommodative strategies of coping. Psychology and Aging, 5, 58-67.

Brim, O. G., \& Kagan, J. (1980). Constancy and change: A view of the issues. In O. G. Brim \& J. Kagan (Eds.), Constancy and change in human development (pp. 1-25). Cambridge, MA: Harvard University Press.

Brown, T. A., Cash, T. F., \& Mikulka, P. J. (1990). Attitudinal body image assessment: Factor analysis of the Body-Self Relations Questionnaire. Journal of Personality Assessment, 55, 135-144.

Carstensen, L. L., Pasupathi, M., Mayr, U., \& Nesselroade, J. R. (2000), Emotional experience in everyday life across the adult life span. Journal of Personality and Social Psychology, 79, 644-655.

Charles, S. T., Reynolds, C. A., \& Gatz, M. (2001). Age-related differences and change in positive and negative affect over 23 years. Journal of Personality and Social Psychology, 80, 136-151.

Cross, S., \& Markus, H. (1991). Possible selves across the life span. Human Development, 34, 230-255.

Emmons, R. A., \& King, L. A. (1988). Conflict among personal strivings: Immediate and long-term implications for psychological and physical wellbeing. Journal of Personality and Social Psychology, 54, 1040-1048.

Freund, A. M. (2006). Differentiating and integrating levels of goal representation: A life-span perspective. In B. R. Little, K. Salmela-Aro, \& S. D. Phillips (Eds.), Personal project pursuit: Goals, action, and human flourishing (pp. 247-270). Mahwah, NJ: Erlbaum.

Freund, A. M., \& Baltes, P. B. (2002). Life-management strategies of selection, optimization, and compensation: Measurement by self-report 
and construct validity. Journal of Personality and Social Psychology, 82, 642-662.

Gollwitzer, P. M., Fujita, K., \& Oettingen, G. (2004). Planning and the implementation of goals. In R. Baumeister \& K. Vohs (Eds.), Handbook of self-regulation research (pp. 211-228). New York: Guilford Press.

Gross, J. J., Carstensen, L. L., Pasupathi, M., Tsai, J., Goetestam Skorpen, C., \& Hsu, A. Y. C. (1997). Emotion and aging: Experience, expression, and control. Psychology and Aging, 12, 590-599.

Henderson, M. D., Gollwitzer, P. M., \& Oettingen, G. (2007). Implementation intentions and disengagement from a failing course of action. Journal of Behavioral Decision Making, 20, 81-102.

Higgins, E. T., Klein, R. L., \& Straumann, T. J. (1987). Self-discrepancies: Distinguishing among self-states, self-state conflicts, and emotional vulnerabilities. In K. Yardley \& T. Honess (Eds.), Self and identity: Psychosocial perspectives (pp. 173-186). Chichester, England: Wiley.

Horley, J., \& Lavery, J. J. (1995). Subjective well-being and age. Social Indicators Research, 34, 275-282.

Kehr, H. M. (2003). Goal conflicts, attainment of new goals, and wellbeing among managers. Journal of Occupational Health Psychology, 8 , 195-208.

Krull, J. L., \& MacKinnon, D. P. (2001). Multilevel modeling of individual and group level mediated effects. Multivariate Behavioral Research, 36, 249-277.

Lawton, M. P., Kleban, M. H., \& Dean, J. (1993). Affect and age: Cross-sectional comparisons of structure and prevalence. Psychology and Aging, 8, 165-175.

Levenson, R. W., Carstensen, L. L., \& Gottman, J. M. (1993). Long-term marriage: Age, gender, and satisfaction. Psychology and Aging, 8, 301-313.

Li, Y., Schneider, J. A., \& Bennett, D. A. (2007). Estimation of the mediation effect with a binary mediator. Statistics in Medicine, 26, $3398-4214$.

Locke, E. A., Smith, K. G., Erez, M., Chah, D.-O., \& Schaffer, A. (1994). The effects of intra-individual goal conflict on performance. Journal of Management, 20, 67-91.

Loewenstein, G. (1996). Out of control: Visceral influences on behavior. Organizational Behavior and Human Decision Processes, 65, 272-292.

Michalak, J., Heidenreich, T., \& Hoyer, J. (2004). Goal conflicts: Concepts, findings, and consequences for psychotherapy. In W. M. Cox \& E. Klinger (Eds.), Handbook of motivational counseling: Concepts, approaches, and assessment (pp. 83-98). Chichester, England: Wiley.

O'Connor, K., de Dreu, C. K. W., Schroth, H., Barry, B., Lituchy, T. R., \& Bazerman, M. H. (2002). What we want to do versus what we think we should do: An empirical investigation of intrapersonal conflict. Journal of Behavioral Decision Making, 15, 403-418.

Reis, H. T., Sheldon, K. M., Gable, S. L., Roscoe, J., \& Ryan, R. M. (2000). Daily well-being: The role of autonomy, competence, and relatedness. Personality and Social Psychology Bulletin, 26, 419-435.

Riediger, M. (2007). Interference and facilitation among personal goals: Age-group differences and associations with well-being and behavior. In B. R. Little, K. Salmela-Aro, J.-E. Nurmi, \& S. D. Philipps (Eds.), Personal project pursuit: Goals, action, and human flourishing (pp. 119-143). Mahwah, NJ: Erlbaum.

Riediger, M., \& Freund, A. M. (2004). Interference and facilitation among personal goals: Differential associations with subjective well-being and persistent goal pursuit. Personality and Social Psychology Bulletin, 30, $1511-1523$.

Riediger, M., \& Freund, A. M. (2006). Focusing and restricting: Two aspects of motivational selectivity in adulthood. Psychology and Aging, 21, 173-185.

Riediger, M., Freund, A. M., \& Baltes, P. B. (2005). Managing life through personal goals: Intergoal facilitation and intensity of goal pursuit in younger and older adulthood. Journals of Gerontology, Series B: Psychological Sciences, 60, P84-P91.

Riley, M. W., Kahn, R. L., \& Fohner, A. (Eds.). (1994). Age and structural lag: Society's failure to provide meaningful opportunities for work, family, and leisure. New York: Wiley.

Sackeim, H. A. (1983). Self-deception, self-esteem, and depression: The adaptive value of lying to oneself. In J. Masling (Ed.), Empirical studies of psychoanalytic theory (Vol. 1, pp. 101-157). Hillsdale, NJ: Analytic Press.

SAS Institute. (2002). SAS for Windows (Version 9.1.3) [Computer software]. Cary, NC: Author.

Settersten, R. A., Jr., \& Hagestad, G. O. (1996a). What's the latest? Cultural age deadlines for family transitions. The Gerontologist, 36 , $178-188$.

Settersten, R. A., Jr., \& Hagestad, G. O. (1996b). What's the latest? II. Cultural age differences for educational and work transitions. The Gerontologist, 36, 602-613.

Singer, J. D., \& Willet, J. B. (2003). Applied longitudinal data analysis. Modeling change and event occurrence. New York: Oxford University Press.

Stacey, C. A., \& Gatz, M. (1991). Cross-sectional age differences and longitudinal change on the Bradburn Affect Balance Scale. Journals of Gerontology, Series A: Biological Sciences and Medical Sciences, 46, M76-M78.

Staudinger, U. M. (2000). Viele Gründe sprechen dagegen, und trotzdem geht es vielen Menschen gut: Das Paradox des subjektiven Wohlbefindens [Many reasons speak against it, yet many people feel good: The paradox of subjective well-being]. Psychologische Rundschau, 51, 185-197.

Staudinger, U. M., Freund, A. M., Linden, M., \& Maas, I. (1999). Self, personality, and life regulation: Facets of psychological resilience in old age. In P. B. Baltes \& K. U. Mayer (Eds.), The Berlin Aging Study: Aging from 70 to 100 (pp. 302-328). New York: Cambridge University Press.

Steyer, R., Schwenkmezger, P., Notz, P., \& Eid, M. (1997). Der mehrdimensionale Befindlichkeitsfragebogen (MDBF): Handanweisung [The Multidimensional Affect Rating Scale (MDBF): Manual]. Göttingen, Germany: Hogrefe.

Van Ness, P. H., O'Leary, J., Byers, A. L., Fried, T. R., \& Dubin, J. (2004, May). Fitting longitudinal mixed effect logistic regression models with the NLMIXED procedure. Paper presented at the Proceedings of the 29th Annual SAS Users Group International Conference, Montreal, Canada.

Wrosch, C., Heckhausen, J., \& Lachman, M. E. (2000). Primary and secondary control strategies for managing health and financial stress across adulthood. Psychology and Aging, 15, 387-399.

Received January 24, 2008

Revision received April 25, 2008 Accepted June 25, 2008 